\title{
Network Ethics: Information and Business Ethics in a Networked Society
}

ABSTRACT. This article brings together two research fields in applied ethics - namely, information ethics and business ethics- which deal with the ethical impact of information and communication technologies but that, so far, have remained largely independent. Its goal is to articulate and defend an informational approach to the conceptual foundation of business ethics, by using ideas and methods developed in information ethics, in view of the convergence of the two fields in an increasingly networked society.

KEY WORDS: business agent, business process, ethical principles, information ethics, infosphere, networked society, network ethics, profit

\section{Introduction}

Information and communication technologies (ICTs) have profoundly changed many aspects of life, including the nature of entertainment, work, communication, education, health care, industrial production, business, social relations and conflicts. Therefore, they have had, and continue to have, a deep, widespread and increasing influence on our moral lives and on contemporary ethical debates (Floridi, 2007a, b). The goal of this article is to bridge two research fields in applied ethics - namely, information ethics (henceforth IE) and business ethics (henceforth BE) - which deal with the ethical

A first version of this article was presented at 'Network Ethics: The New Challenge in Business, ICT, and Education', the second in a series of biennial conferences on ethical issues of technology in business, education and society, organised by the Center for Ethics Business and Economics (CEBE) of the Catholic University of Lisbon - FCEE, Carnegie Mellon University, and the University of Northern Iowa, and held at the Catholic University of Lisbon, Portugal, June 23-25, 2009. impact of ICTs but that, so far, have remained largely independent. The task is made pressing by the realisation that we live in a networked society in need of a distributed, information-based business ethics. This is not to say that IE and BE have not been conversing for some time (see, for example, Coates, 1982; Langford, 1999). It goes without saying that the emergence of a global information society, with its ICT-based ethical challenges, and the growing importance of ICT-intensive and networked business interactions, have made academic and practical barriers between IE and BE increasingly porous (De George, 2003, 2006). Nor does it mean that ethicists, policy makers, lawyers, and businesses more generally have failed to recognise the intrinsically hybrid nature of many key ethical issues. It is widely acknowledged that privacy, copyright, informed consent, transparency and disclosure, P2P, digital divide, and so forth (Ennals, 1994; Mason et al., 1995; Vaccaro, 2006; Vaccaro and Madsen, 2009) can be fully understood only if they are placed at the intersection between IE and BE (Hodel et al., 1998). Rather, the exact point in question is that, despite their obvious commonalities, overlapping interests and joint concerns (Wong, 2000), IE and BE have not yet converged on a shared, conceptual foundation of their investigations. Such common roots are what I hope to disclose in the following pages, which are structured as follows.

In section 'From information ethics to business ethics: a methodological contribution', I shall provide an outline of IE. The focus will be intentionally limited to only those features that will be useful to approach BE informationally. In section 'The informational analysis of business', I shall develop an informational analysis of business agents and processes. This will lead, in section 'The WHI ethical questions: what, how and impact', to the identification of the three main ethical questions to be 
addressed by an information-based business ethics, namely:

(1) What goods or services are provided?

(2) How are they provided? and

(3) What impact do (1) and (2) have?

Answers to these questions offer evidence about the moral performance of the system. However, in order to motivate, prompt or cause the system to improve its behaviour, one has to identify the main points where normative pressure can be exercised. Such points are analysed in section 'Normative pressure points'. In section 'The ethical business: from IE to BE', I shall argue that profit is neither part of the definition, nor the function, of business, but a goal that provides no ethical input by itself. Instead, in order to understand what it means for a business to be morally good, we need to understand its deepest philosophical roots (ontology), and realise that business is an ethically good force in so far as it embodies human tension between being in favour of systemic growth and well-being, and against wastefulness (of opportunities, of resources, of demands, of supplies, and so forth), that is, in favour of the flourishing of, and against the destruction, corruption, pollution and depletion of (parts of) the natural and man-made environment in which a business operates. I shall therefore argue that a business agent is increasingly morally good the more successful it is in implementing four pro-flourishing and anti-wastefulness principles, mediated from IE. In the conclusion, I shall offer a positive note about the respectful, caring, but also fostering and constructionist role that business agents may play as stewards for the realities that they can positively affect.

\section{From information ethics to business ethics: a methodological contribution}

The informationalization of our environment, of human society and of ordinary life has created entirely new realities, made possible unprecedented phenomena and experiences, provided a wealth of extremely powerful tools and methodologies, raised a wide range of unique problems and conceptual issues, and opened up endless possibilities hitherto unimaginable. As a result, it has also deeply affected our moral choices and actions, affected the way in which we understand and evaluate moral issues and posed fundamental ethical problems, whose complexity and dimensions are rapidly growing and evolving. It would not be an exaggeration to say that many of the new ethical problems we are facing today are related to the information revolution.

Readers of this journal do not need to be introduced to the nature and scope of BE. In general, I agree with Martin and Freeman (2004) when they argue that 'business ethicists are uniquely positioned to analyse the relationship between business, technology, and society'. However, the same readers might be less well acquainted with IE. In recent years, IE has emerged as the theoretical foundation of applied computer ethics (Floridi, 1999a), the discipline that deals with ICT-based ethical issues (Moor, 1985). Providing even a short introduction to IE lies well beyond the scope of this article. ${ }^{1}$ The relevant point here is that IE offers an innovative and flexible methodology, which turns out to be particularly well-suited to model some foundational aspects of $\mathrm{BE}$ in the new context of a highly networked society. Such methodological approach is based on four main features, which can be briefly outlined as follows.

(1) The nature of moral agents (Floridi and Sanders, 2004). IE defends a much less anthropocentric concept of agents, which also include non-human (artificial) and non-individual (distributed) entities, as well as networked, multiagent systems and hybrid agents (e.g. companies and institutions). This goes hand in hand with BE's stress on business organizations as ethical agents in and of themselves.

(2) The nature of moral receivers (Floridi, 2003). IE argues in favour of a more inclusive and less biologically biased concept of potential receivers of moral actions as 'centres of ethical worth', which now encompasses not only humans or living entities, but also engineered entities and their networks. Again, this is in tune with BE's interest in the fate of business organizations as well as with BE's expansion of the concept of receivers to include not only shareholders, but also stakeholders of various kinds (Freeman, 1984). This allows the expansion of classic stakeholder theory (Phillips, 2003) to informational entities, the fabric of their networks and, ultimately, to the whole environment or infosphere (more on this below). 
(3) The nature of the environment. IE offers an informational, network-based conception of the environment, which now includes both natural and artificial (synthetic, man-made) eco-systems. This is known as infosphere. The term denotes the whole environment understood informationally, that is, as constituted by all informational entities (thus also including informational agents like us or like companies, governments, etc.), their properties, and the network of their interactions, processes and mutual relations. The infosphere is an environment, and hence a concept, that is rapidly evolving. The alert reader will notice a shift from a semantic (the infosphere understood as a space of contents) to an ontological conception (the infosphere understood as a networked environment populated by informational entities).

(4) The nature of the moral relations and interactions. IE supports an environmental, receiver-oriented approach. It is the well-being of the receiver of the moral action that, in principle, ought to contribute to the possible guidance of the agent's ethical decisions, and potentially constrain and orient the agent's moral behaviour. The receiver of the action is placed at the core of the ethical discourse, at the centre of the ethical network, while the 'transmitter' of any moral action (the agent), is moved to its periphery. This approach resonates with a variety of BE's more advanced views, which can be employee-, customer-, shareholderand stakeholder-centred (Agle et al., 2008).

These four features make IE and BE highly compatible and invite the application of IE to the informational analysis of $\mathrm{BE},{ }^{3}$ as we shall see in the next section.

\section{The informational analysis of business}

Our first step consists in revisiting the definition of 'business' from a network-based informational perspective. There are, of course, two main senses to be taken into account: business as an agent, that is, as a node in the network, and business as an activity, that is, as a relational process in the network. The standard definition of 'business' as an agent states that

$$
\begin{aligned}
& \text { Business (agent) } \\
& =_{\text {def. the provider of goods or services }} \\
& \quad \text { to customers. }
\end{aligned}
$$

When 'business' is to be understood as a process, activity or interaction, rather than as the agent that is its source, the following definition is equally unproblematic:

$$
\begin{aligned}
& \text { Business (activity) } \\
& ={ }_{\text {def. }} \text { the provision of goods or services } \\
& \quad \text { to customers. }
\end{aligned}
$$

Although (1) and (2) are uncontroversial, the reader will notice that they contain no reference to profit, which therefore turns out to be a feature that is neither necessary nor sufficient to qualify something as a business agent or process. The importance of this remarkable absence is not often appreciated in full, and I will return to it later in the article. At this stage, (1) and (2) may seem obvious, but that is the nature of all starting points of an adequate logical analysis: they should be uncontroversial to the point of being trivial. What follows immediately from (1) and (2) is that one can define business agents as the source of business activities. Wherever some provision of goods or services to customers occurs, there we find a business agent, whether this is an individual selling coconut water on a beach, a school offering tuition, or a multinational corporation refining crude oil.

Once (1) is understood on the basis of (2), it becomes possible to analyse (2) in relational terms: the agent is defined in terms of the activity that characterises it, and the activity is defined in terms of the ternary ${ }^{4}$ relation that constitutes it. To put it simply, we want to be able to state that $x$ counts as a business if and only if, if $x$ is an agent and $y$ is a good or service and $z$ is a customer, then $x$ provides $y$ to $z$. Using classic, first-order predicate logic and the following abbreviations:

$$
\begin{gathered}
A(x)=x \text { is an agent } \\
B(x)=x \text { is a business } \\
C(z)=z \text { is a customer } \\
D(y)=y \text { is a (deliverable) good or service } \\
P(x, y, z)=x \text { provides } y \text { to } z
\end{gathered}
$$

we obtain:

$$
\begin{aligned}
\forall x \forall y \forall z(B(x) & \leftrightarrow((A(x) \wedge D(y) \wedge C(z) \\
& \rightarrow P(x, y, z))))
\end{aligned}
$$


The formula in (3) expresses more precisely what is stated above more informally. The advantage is that it makes it easier to appreciate four major features that we shall need in the rest of the article.

First, (3) shows that it is perfectly possible to have cases in which $x=y=z$. In other words, this means that the three variables could be replaced by the same constant, as in the extreme (and rather unlikely) case in which a business sells (parts of) itself to (some other parts of) itself. Of course, normally $x$, $y$ and $z$ will be interpreted as different constants. This is as it should be, since our model would be extremely inadequate if it could not accommodate the rather common case in which a business sells a product, which could also be a business, to a customer, which could also be another business. In short, the formula allows for the highest degree of interpretative flexibility.

Second, (3) is process- or relation-centred, as required above: first comes the concept of business as a transaction, which then defines the related elements as business agent and customer, not vice versa.

Third, from (3), it is simple to obtain a customercentred (or receiver-centred) model, as illustrated by Figure 1 below.

Finally, one can apply to (3) a standard reduction theorem in predicate logic, which proves that

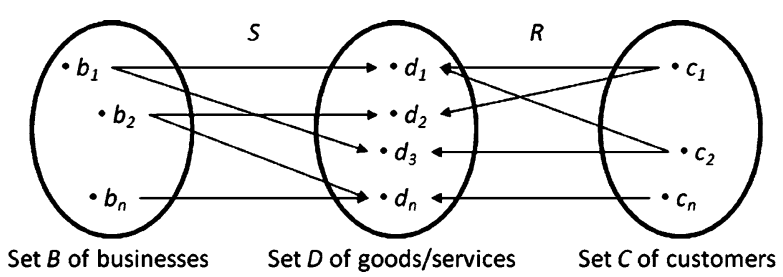

Figure 1. The relational analysis of business. ternary relations can be reduced to combinations of binary relations, e.g. by transforming ' 3 is between 2 and 4 ' into " " 3 is bigger than 2 ' and ' 3 is smaller than 4"'. It follows that, although it might seem that business as an activity might necessarily require a ternary relation $P$ in order to connect three, nonempty sets of related elements - namely $B$, constituted by the business agents, $C$, constituted by the customers, and $D$, constituted by the deliverable goods and services - one can actually transform $P$ into a conjunction of two relations $S$ and $R$ without any loss of logical adequacy. The economic interpretation of $S$ and $R$ would normally be in terms of 'supplying' and 'demanding'. Given the informational approach adopted in this article, we shall use a different semantics and read $S$ as 'sending' and $R$ as 'receiving'. The result is shown in Figure 1.

We are now ready to simplify the analysis further and obtain the initial model that, once transformed from static to dynamic, will serve us for the rest of the article. I shall refer to it as the concentric ring model (see Figure 2). Note that this is not a Venn diagram, where the smaller unit is completely contained within the larger one, nor a 'layer' diagram, like a cake. Rather the three sets $C, D, B$ could be seen as three doughnuts. $C$ is like a filled doughnut. It is surrounded by $D$, which can be imagined to be similar to a ring doughnut (technically, a torus). In its turn, $D$ is surrounded by $B$, also shaped like a ring doughnut. The threshold between $C$ and $D$ is the relation $R$, and the threshold between $D$ and $B$ is the relation $S$. We have finally obtained an accurate but also intuitive representation, as a single object, of our logical model in Figure 1.

The concentric ring model, illustrated in Figure 2, places customers at the centre of all business activities.

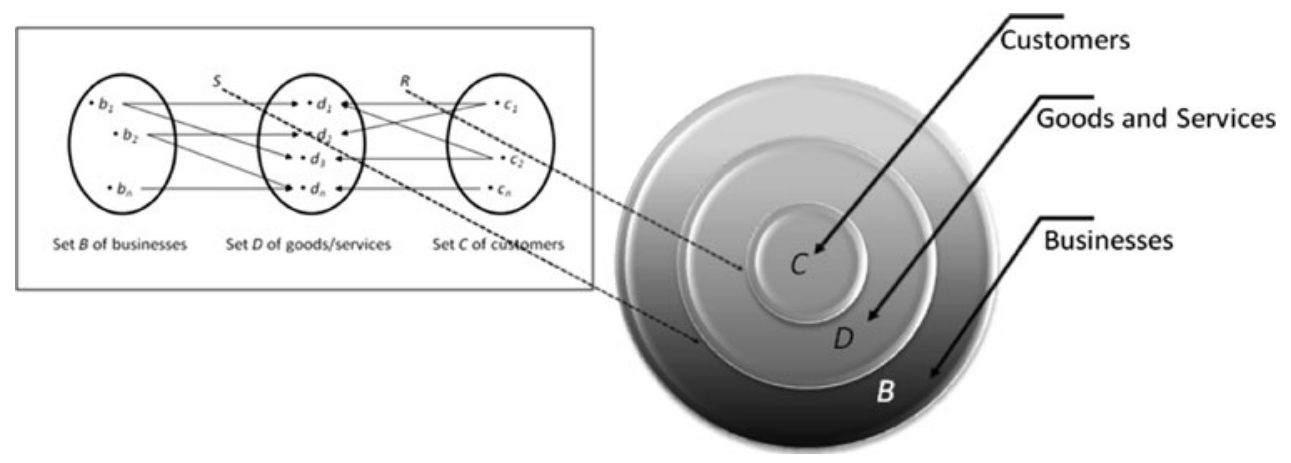

Figure 2. The concentric ring model of business. 
This is a valuable feature. The model further highlights the absence not only of profit as part of the definition of business (whether as an agent or as an activity it does not matter), as expected, but also of two other aspects that have been extensively discussed in the literature on business ethics: the problem of (fair) prices, which now appear to be a property of elements of $D$, and the nature/identity of business agents, that is, the elements of the set $B$, now defined as the sources of good/services. The model, however, still has one major limit: it is merely static. Hence, it fails to take into account the interactions between business agents and customers over time and within a shared, networked environment. This is the last refinement that needs to be provided.

The parameters in our dynamic model are obviously time (the $x$ axis) and the number of interactions between the various elements (the $y$ axis). By placing the concentric ring models or whirlpools (their influence on the surrounding environment proceeds like decreasing waves), obtained above, in such a $2 \mathrm{D}$ space, we finally reach a more accurate description of the development of business interactions in real life, one which will suffice to explain and discuss critically the analysis developed in the rest of the article. I shall refer to this model as the whirlpool model. Figure 3 provides an illustration. Note that it is like a snapshot of a dynamic system: the whirlpools should be imagined as constantly increasing and then decreasing.

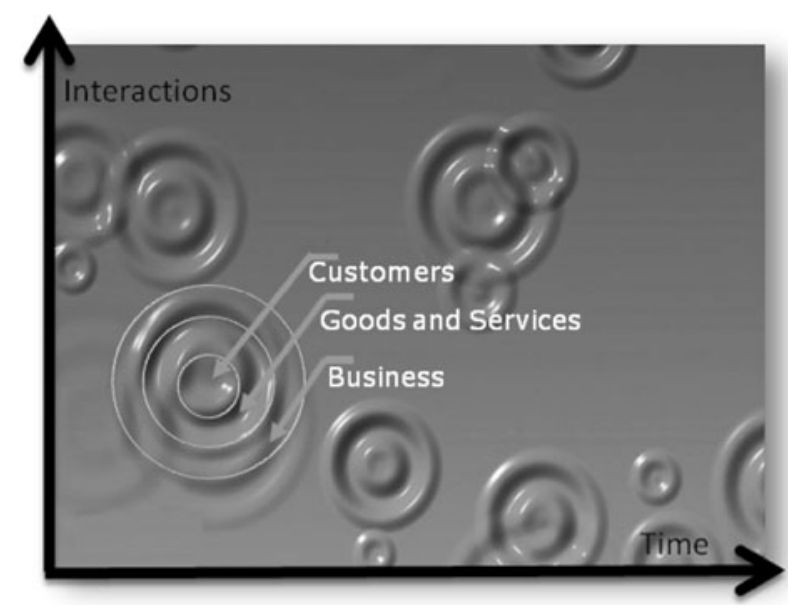

Figure 3. The whirlpool model of business.
We now have a sufficiently detailed analysis of the object whose properties need to be investigated. Given the complex, informational, networked scenario represented by the whirlpool model, what are the main kinds of ethical questions faced by business agents? This is the key issue addressed in the next section.

\section{The WHI ethical questions: what, how and impact}

Consider Figure 3. It seems evident that the fundamental questions to be addressed by an informationally modelled BE concern:

(1) What goods/services are provided?

(2) How are they provided?

(3) What impact do (1) and (2) have on both natural and artificial environments?

Figure 4 illustrates how the questions may be located in our model. Let me briefly comment on each of them.

By asking (1), an ethical theory concentrates on the product and hence shows that questions regarding the moral nature of the sender ('is the so and so business agent/source morally good or evil?’) are still important but can be dealt with as secondary. This is perfectly in line with mainstream ethical theories, which consider 'good' and 'evil' as properties qualifying primarily actions and their outcomes, and only secondarily their sources. We qualify someone as mainly good or evil depending on whether his or her actions or their effects are mainly evil or good. Accordingly, in our model, business agents, their states and plans, are identified as morally good or evil not in themselves, but only in a derivative sense, that is, following the assessment of their actions and the corresponding outcomes.

By asking (2), the same ethical theory addresses the moral nature of the process that leads to a particular output. Whereas question (1) concerns the nature of the elements of the set $D$, question (2) concerns the nature of the relation $S$ between $B$ and $D$.

Finally, no ethical analysis would be complete without a careful investigation of question (3), that is, the impact that the supply of specific goods/services, and hence the presence of goods/services 


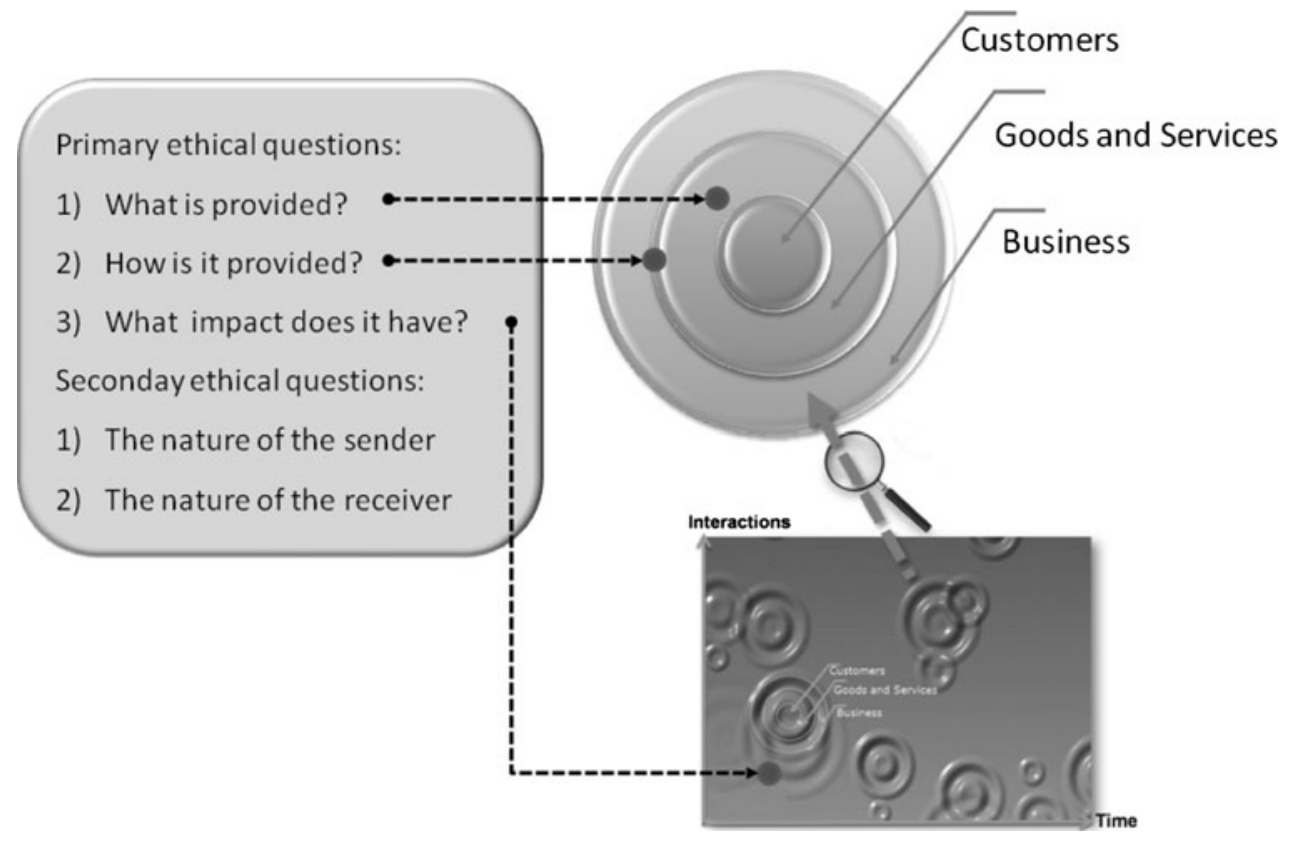

Figure 4. The WHI ethical questions: what, how and impact.

themselves, have on the networked environment within which the business agents operate in interplay with their customers.

Depending on how one answers questions (1)(3), there follows a different ethical evaluation of the business agent under investigation. However, if one wishes to modify that agent's behaviour, the WHI questions are of little help. They might signal that something needs to be done, but they cannot help in achieving the required modifications. For such a pragmatic goal, the whirlpool model needs to identify what one may call the right points of normative pressure, the topic of the next section.

\section{Normative pressure points}

We have just seen what the most fundamental ethical questions that might be asked in $\mathrm{BE}$ are, when $\mathrm{BE}$ is approached from an IE perspective. I also anticipated that it would be a mistake to think that they are also the points where normative pressure can be exercised on the system. Answers to the WHI questions may indicate how well (or indeed how badly) the overall system is performing, morally speaking, but they only contribute informatively to the process of guiding and shaping the system.
Pragmatically, insofar as the processes of motivating, fostering, causing or preventing new conducts are concerned, we need to identify ways in which the performance of the system may be successfully affected. In other words, we need to identify the main points where normative pressure can be exercised with some hope for success. Such points are three (or a combination of them) since, ideally, normative pressure should be exercisable on each of the three sets constituting the model (see Figure 4).

(1) Educational pressure on $C$. One might exercise pressure on the system by educating or informing customers about the answers to the WHI questions. The availability, accessibility and transparency of more and better information about

- what goods/services are provided,

- how they are provided, and

- the impact that their provision has, or might have, on the overall environment or infosphere,

helps customers to make and shape their choices, and hence provides a significant way of influencing the moral behaviour of business agents. This is what drives not only standard competition, but also phenomena such as ethical consumerism and fair trade certification (Crane and Matten, 2007). 
(2) Prescriptive pressure on $D$. The system may also be influenced by indicating what goods/services ought to be (of course both positively and negatively). This often means identifying requirements, specifications or standards that ought to be satisfied by the provided goods/services. We shall see that quality certification and control, as well as the indication of what features goods/services should or should not have, can be not only an ethical but also a legal issue.

(3) Proscriptive pressure on B. Finally, business agents may be influenced directly, through moral (or legal, see below) proscriptions about what ought not to be done.

As anticipated, in each of the previous three cases pressure can be exercised not only morally, but also legally. The point is worth clarifying. So far, we have analysed the ethical business system as if only two types of agents were involved in the network, businesses, interpreted as senders, and customers, interpreted as receivers. The State (and by this I mean to refer to any entity with the legal power and legitimacy to impose its decisions on the whole whirlpool system, at least in principle) represents a third set of agents. Ideally, by issuing laws, imposing sanctions or disincentives and offering rewards or incentives, the State is expected to play the role of facilitator, regulator and referee of the communication system. Thus, the role of a liberal State in a modern democracy is proscriptive and proactive when it comes to the behaviour of business agents: it focuses on what business agents should not do (the legal don'ts) and on incentives to facilitate specific behaviours which are morally good or beneficial to the whole system or society. However, the role becomes prescriptive and reactive when the goods or services provided are concerned: the liberal State legislates on what they ought to be (the legal dos) and on the sanctions that might be imposed, if such legislation is not respected. The State's intervention in the network is usually hugely influential, as it adds a third dimension: the system acquires not only ethical norms but also legal rules or laws, and hence corresponding incentives, disincentives, prohibitions and sanctions (Nelson, 2006). Of course, ethical norms aim at inviting endorsement, whereas legal rules seek to enforce compliance. The former are supposed to foster moral behaviour, the latter might be entirely neutral about it. How does this third dimension affect our model? An example will help to clarify the issue.
Consider the tobacco industry and more specifically the cigarette business. $B$ is represented by tobacco companies, which send (i.e., produce and sell) goods in $D$, let us say cigarettes, which are received (i.e., bought) by $C$, individual customers. Answers to the three WHI ethical questions are well known and do not have to be rehearsed here. What about the normative pressure points and the State's intervention? Through taxation, the setting of age limits, the indication of non-smoking areas or the constraint on advertising forms and targets, the State exercises an external control on the system which is not, in and of itself, of a moral nature, but that has the function of facilitating moral behaviour. There is nothing intrinsically right or wrong, morally speaking, in smoking a cigarette in a cinema. By making it illegal, however, the State makes it easier to give up a bad habit, to prevent fire hazards, to diminish passive smoking and so forth, and these effects have a morally positive value, insofar as they are good for the system in general and its individual receivers in particular. Smoking is unhealthy, can easily become an addiction and hence a moral vice, and the State seeks to make the choice of smoking more difficult and responsible, without infringing individual liberties. The same applies to wine, beer and spirits. It should really apply to other recreational drugs as well, such as cannabis. Next, by making it compulsory to provide health information regarding smoking - e.g., health education in schools, documentaries on TV, or health warnings on cigarette packets - the State exercises direct moral pressure on the system through the 'education of $C$ ', one of the normative pressure point discussed above. In terms of prescriptions, the second pressure point, consider the ethical choice of producing only selfextinguishing cigarettes (available since the 30s). This could be a moral choice of the producers, instead of becoming a proactive legal requirement brought about by some legislation, as it is already the case in several American states, such as New York, Massachusetts and California, and it might soon happen in the EU. After all, burning cigarettes are among the main causes of fires. Finally, in terms of proscriptions, 'Joe Camel' provides an illustrative example. In 1987, RJR created Joe Camel as the mascot for the brand of Camel cigarettes. In 1991, the American Medical Association reported that the campaign had been particularly popular among 
5- and 6-year-old, who apparently could recognise Joe Camel more easily than Mickey Mouse, Fred Flintstone, Bugs Bunny or even Barbie (Fischer et al., 1991). This led the association to invite RJR to terminate the Joe Camel campaign. Although RJR initially declined, in 1997, after further appeals, the Joe Camel campaign was replaced by a somewhat more adult campaign. The point is that RJR never lost a legal battle on this issue, but acted in a way that, whatever the ultimate motives might have been, had a positive moral outcome.

\section{The ethical business: from IE to BE}

The previous analysis has provided the formal framework within which $\mathrm{BE}$ can be interpreted informationally. Some of the features of the model already cast a different light on the ethical agenda of $\mathrm{BE}$ in a networked society. Three issues - (1) the nature of business agents, (2) the fairness of prices of goods or services and (3) the obtainment of profit (Friedman, 1970) - have been shown to be of much less pressing concern than (4) the nature of the delivered goods or services, (5) the ways in which they are produced and (6) what impact their provision might have on the overall environment. This is interesting, since it seems that much of contemporary $\mathrm{BE}$ has been focused more on (1)-(3) than on (4)-(6). What the previous formal analysis cannot provide yet is actual content (as opposed to a formal analysis) that is, a coherent vision, based on explicit ethical principles, of what an ethical business in the information society should be like. This is the last but perhaps most important contribution offered by IE.

It seems uncontroversial that, in order to be just and fair, laws and regulations should be at least compatible with, if not directly based on, morally right norms (ethical prescriptions and proscriptions), which in turn may be expected to depend on morally good principles. However, what sort of morally good principles should guide business agents? How are we going to know when the answers to the WHI questions are morally unsatisfactory? And how can we judge whether, and what sort and degree of normative pressure should be exercised, and in which direction, if the behaviour of the agents in the networked system is deemed unsatisfactory and needs to be rectified? Much seems to depend on how we understand the ultimate nature of business itself, its function, goal and role in society, in other words, its deep ontology.

Recall the definition of business given in (1). It applies both to for-profit and to non-profit business organizations. Indeed, following (1), even business organizations with negative net profit do not, for this reason, stop qualifying as business agents. Hence, profit is clearly not part of the essence of a business, not in the sense in which having three sides is part of the essence of a triangle. Unfortunately, this point is often overlooked, by objecting that, being profitable might not be part of the nature of what may count as business, but it does capture its basic or primary function. At least in the case of for-profit enterprises, that very qualification refers exactly to what the task or function of a business is, although not its necessary and sufficient conditions. If this is granted, then one might further argue that the function, i.e., profit, determines the moral quality of the function-bearer, namely the business. With an analogy, our opponent might argue that the definition of a knife does not include 'being sharp', but since a knife's function is to cut, then the sharper the knife is the better it cuts, and so the better that knife should be judged to be.

The reasoning is, once again, muddled, for it fails to distinguish between a functional analysis ('for cutting') and a teleological analysis (cutting in order to achieve which goal?). Suppose, just for a moment, that profitability could qualify as the primary function of business. A sharp knife is a very good knife functionally speaking, but a morally bad tool in the hands of a serial killer. A very profitable business would be a very good business functionally speaking, but still a moral tragedy if run by a child-pornographer. Clearly, if profit is understood as the function of business, this leaves unanswered any moral question worth asking. We have begun to rectify the confusion. From a functional perspective, profit may be (and often is) the much desired effect of a wellrun business, whose primary function, nevertheless, remains that of providing goods and services to customers. If the distinction is unclear, the following analogy should help. People who argue that profit is the primary function of business are as mistaken as those who argue that the primary function of sexual intercourse is pleasure. Naturally, pleasure plays a very important and positive role, and of course 
animals may pursue sexual pleasure only for its own sake or, in the case of humans, for mental reasons as well. All this, however, should not blind us to the fact that sexual intercourse has a reproductive function.

So far we have established that profit is neither part of the essence nor the function of business. Recall that we are trying to understand on which moral principles a business could be ethically evaluated. Now, our opponent has a further reply. Let us admit that the distinction between essence, function and goal of a business is sound. Profit might be transformed into the teleological goal of a business, that is, into its purpose or mission. A morally good business would then be one that takes due care of its goal being profitable - in view of the advantage that this brings for its shareholders. Here, we find the most dangerous mistake, because it is the least visible. First, let me clarify a final point about the function of business. Above, we assumed that profit could play such a role. We conceded this only for the sake of argument. Our opponent has now reinterpreted profit as playing the role of a business' goal. This has left empty the role of function. We know from (1) and (2) that the function of business is to provide goods and services to customers. Like the knife before, the more successful a business is, in providing goods or services to its customers, the better it is functionally speaking. Notice, however, that our opponent is still waiting for an answer to his objection that profit might be the purpose orientating the function. This requires one further distinction.

It is a fact that most, if not all, businesses have profit as their main, if not only, ostensible goal. This fact, however, should not mislead us into thinking that we have finally hit upon the foundation for an ethical evaluation. Consider the difference between:

(a) what is good for $x$; and

(b) what $x$ is good for.

We are interested in the case in which $x=$ business. Following (a), profit is certainly what is good for business. Without it, business can much less easily grow in size, develop in quality and flourish as a rewarding and successful enterprise for the people involved. Yet this is a factual remark, similar to what we said above about the sharp knife. Profit, in this sense, still does not draw any difference between morally good or evil businesses. For profit is ethically blind: it rewards any business that pursues it successfully. Profit would still be a good thing for business even if the business were that of trading slaves. The ethical question is addressed once we move to (b). What is the business, for which profit is indeed a good thing, good for? The answer must arguably come from a consideration of the contribution made by the business in question to the network in which it is embedded, its overall environment, by which I mean not just its physical or natural habitat, but ultimately the whole ecosystem affected by that business, by its practices and its products or, in the informational vocabulary of IE, the region of the infosphere that is affected by that business. Of course, (b) can be answered purely factually, by arguing that profit is what business is good for. In this case, there is no circularity but rather mere consistency. The problem is not logical, but conceptual: we are still failing to touch upon the moral question. Profit is good for business and business is good for profit. The ethical blindness is still there, as we are still unable to distinguish between a morally good and a morally evil business. In order to provide such a normative evaluation, we need to address (b) in such a way as to step into the realm of ethical principles. We need to decide what a business is morally good for. This is the deeper ontological question that really matters, ethically speaking, and it is one that, following IE, can be addressed from a receiver-oriented perspective.

From the receiver-oriented perspective supported by IE, business is the art of matching supply and demand and, in so doing, fostering human flourishing and avoiding wastefulness. By wastefulness I mean any kind of destruction, corruption, pollution and depletion of (parts of) reality, that is, any form of impoverishment on the side of the receivers of the business activities. It follows that a business agent is increasingly morally good the more successful it is in implementing the following environmental principles, mediated by a more abstract and inclusive analysis provided by IE:

1. wastefulness ought not to be caused in the world (the infosphere)

2. wastefulness ought to be prevented in the world (the infosphere)

3. wastefulness ought to be removed from the 
world (the infosphere)

4. the flourishing of entities as well as of the whole infosphere ought to be promoted by preserving, cultivating and enriching their properties.

Following the analysis developed in this article, these four principles play a twofold role. On the one hand, they can provide clarification when answers to the WHI questions are morally unsatisfactory. On the other hand, they can indicate how the behaviour of the overall system could be improved. To put it more simply, they can be used as a yardstick to tell when business matters are not going morally well, and how they can be rectified to go morally better.

\section{Conclusion}

We are living in a networked environment (infosphere) that is becoming increasingly synchronised (time), delocalised (space) and correlated (interactions). Previous revolutions (especially the agricultural and the industrial ones) created macroscopic transformation in our social structures and physical environments, often without much foresight. The informational revolution is no less dramatic. We shall be in deep trouble if we do not take seriously the fact that we are constructing the new environment that will be inhabited by future generations (Floridi and Sanders, 2005). We should be working on an ecology of the infosphere (Floridi, 2007a, b). Unfortunately, I suspect it will take some time and a whole new kind of education and sensitivity to realise that the infosphere is a common space, which needs to be preserved and improved to the advantage of all (for advancements in this direction see, for example, Wood and Logsdon, 2008). One thing seems unquestionable though: business is part of the human exception (Floridi, 2006). Perhaps even more than the use of language or tools, we are the only animals that do business (other animals trade favours at most, they do not engage in financial transactions). Hence, civilizations and societies are often evaluated on the basis of how friendly they have been towards this special feature of human life. It is to be hoped that the information society will be judged, by future generations, as business-friendly, and that such friendliness will be repaid by the re- spect and care exercised towards the infosphere by the business agents inhabiting it (Crane and Matten, 2004).

\section{Notes}

1 The interested reader might wish to consult Bynum (2001), Tavani (2007) or Floridi (2008)).

2 Infosphere is a neologism I coined in the 90s on the basis of 'biosphere', a term referring to that limited region on our planet that supports life. See, for example, Floridi (1999b) or http://en.wikipedia.org/wiki/Infosphere.

3 See Pierce (1980) or Floridi (2010).

4 This is a relation that needs three elements to be satisfied, such as Germany is between France and Poland.

\section{References}

Agle, B. R., T. Donaldson, R. E. Freeman, M. C. Jensen, R. K. Mitchell and D. J. Wood: 2008, 'Dialogue: Toward Superior Stakeholder Theory', Business Ethics Quarterly 18(2), 153-190.

Bynum, T.: 2001, 'Computer Ethics: Basic Concepts and Historical Overview', The Stanford Encyclopedia of Philosophy (online).

Coates, J. F.: 1982, 'Computers and Business - A Case of Ethical Overload', Journal of Business Ethics 1(3), 239248.

Crane, A. and D. Matten: 2004, Business Ethics: A European Perspective: Managing Corporate Citizenship and Sustainability in the Age of Globalization (Oxford University Press, Oxford, UK).

Crane, A. and D. Matten: 2007, Business Ethics: A European Perspective: Managing Corporate Citizenship and Sustainability in the Age of Globalization, 2nd Edition (Oxford University Press, Oxford, UK).

De George, R. T.: 2003, The Ethics of Information Technology and Business (Blackwell, Malden, MA/Oxford, $\mathrm{UK})$. 
De George, R. T.: 2006, 'Information Technology, Globalization and Ethics', Ethics and Information Technology 8(1), 29-40.

Ennals, J. R.: 1994, Information Technology and Business Ethics (Kingston Business School, Kingston upon Thames, UK).

Fischer, P. M., M. P. Schwartz, J. W. Richards Jr., A. O. Goldstein and T. H. Rojas: 1991, 'Brand Logo Recognition by Children Aged 3 to 6 Years: Mickey Mouse and Old Joe the Camel', The Journal of the American Medical Association 266(22), 31453148.

Floridi, L.: 1999a, 'Information Ethics: On the Philosophical Foundations of Computer Ethics', Ethics and Information Technology 1(1), 37-56.

Floridi, L.: 1999b, Philosophy and Computing: An Introduction (Routledge, London, New York).

Floridi, L.: 2003, 'On the Intrinsic Value of Information Objects and the Infosphere', Ethics and Information Technology 4(4), 287-304.

Floridi, L.: 2006, 'Information Technologies and the Tragedy of the Good Will', Ethics and Information Technology 8(4), 253-262.

Floridi, L.: 2007a, 'Global Information Ethics: The Importance of Being Environmentally Earnest', International Journal of Technology and Human Interaction 3(3), $1-11$.

Floridi, L.: 2007b, 'A Look into the Future Impact of ICT on Our Lives', The Information Society 23(1), 59-64.

Floridi, L.: 2008, 'Information Ethics: Its Nature and Scope', in J. van den Hoven and J. Weckert (eds.), Moral Philosophy and Information Technology (Cambridge University Press, Cambridge, UK), pp. 40-65.

Floridi, L.: 2010, Information - A Very Short Introduction (Oxford University Press, Oxford, UK).

Floridi, L. and J. W. Sanders: 2004, 'On the Morality of Artificial Agents', Minds and Machines 14(3), 349-379.

Floridi, L. and J. W. Sanders: 2005, 'Internet Ethics: The Constructionist Values of Homo Poieticus', in R. Cavalier (ed.), The Impact of the Internet on Our Moral Lives (SUNY, New York).

Freeman, R. E.: 1984, Strategic Management: A Stakeholder Approach (Pitman, Boston, MA).

Friedman, M.: 1970, 'The Social Responsibility of Business is to Increase Its Profits', The New York Times Magazine 13 September.

Hodel, T. B., A. Holderegger and A. Lüthi: 1998, 'Ethical Guidelines for a Networked World under Construction', Journal of Business Ethics 17(9), 10571071.

Langford, D.: 1999, Business Computer Ethics (AddisonWesley, Harlow).
Martin, K. and R. E. Freeman: 2004, 'The Separation of Technology and Ethics in Business Ethics', Journal of Business Ethics 53(4), 353-364.

Mason, R. O., F. M. Mason and M. J. Culnan: 1995, Ethics of Information Management (Sage, Thousand Oaks, CA/London).

Moor, J. H.: 1985, 'What is Computer Ethics?', Metaphilosophy 16(4), 266-275.

Nelson, B. L.: 2006, Law and Ethics in Global Business: How to Integrate Law and Ethics into Corporate Governance Around the World (Routledge, London).

Phillips, R.: 2003, Stakeholder Theory and Organizational Ethics (Berrett-Koehler, San Francisco).

Pierce, J. R.: 1980, An Introduction to Information Theory: Symbols, Signals \& Noise (Dover Publications, New York).

Tavani, H. T.: 2007, Ethics and Technology: Ethical Issues in an Age of Information and Communication Technology, 2nd Edition (Wiley, Hoboken, NJ).

Vaccaro, A.: 2006, 'Privacy, Security, and Transparency: ICT-Related Ethical Perspectives and Contrasts in Contemporary Firms', in D. Howcroft, E. Trauth and J. I. DeGross (eds.), Social Inclusion: Societal and Organizational Implications for Information Systems (Springer, New York), pp. 245-258.

Vaccaro, A. and P. Madsen: 2009, 'Corporate Dynamic Transparency: The New ICT-driven Ethics?', Ethics and Information Technology 11(2), 113-122.

Wong, K.: 2000, 'The Development of Computer Ethics: Contributions from Business Ethics and Medical Ethics', Science and Engineering Ethics 6(2), 245-253.

Wood, D. J. and J. M. Logsdon: 2008, 'Educating Managers for Global Business Citizenship', in D. L. Swanson and D. G. Fisher (eds.), Advancing Business Ethics Education (Information Age Publishing, Charlotte, NC), pp. 265-284.

Luciano Floridi Research Chair in Philosophy of Information, UNESCO Chair in Information and Computer Ethics, and GPI, Department of Philosophy, University of Hertfordshire, de Havilland Campus, Hatfield, Hertfordshire AL10 9AB, U.K. E-mail: l.floridi@herts.ac.uk

Faculty of Philosophy and IEG, University of Oxford, Oxford, U.K. 